\title{
EFEITO DA CASCA DE MAMONA SOBRE A PRODUÇÃO, COMPOSIÇÃO E ÁCIDOS GRAXOS DO LEITE DE CABRA*
}

\author{
EFFECT OF THE CASTOR BEAN HULLS IN THE DAIRY GOAT DIET ON PRODUCTION, \\ CONTENT AND FAT ACID PROFILE OF MILK
}

\author{
Santos, S.F. ${ }^{1 A}$, Bomfim, M.A.D. ${ }^{2 A}$, Cândido, M.J.D. ${ }^{1 B}$, Silva, M.M.C. ${ }^{2 B}$, Pereira, L.P.S. ${ }^{3}$, \\ Souza Neto, M.A. ${ }^{4}$, Garruti, D.S. ${ }^{4}$ e Severino, L.S. ${ }^{5}$
}

'Zootecnia/UFC. Fortaleza-CE. Brasil. Asfsantoszootecnia@gmail.com; ${ }^{B}$ mjdcandido@gmail.com

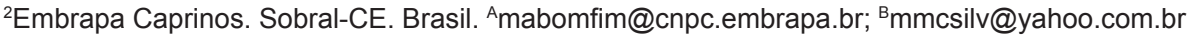
${ }^{3}$ Zootecnia/UVA. Sobral-CE. Brasil.

${ }^{4}$ Embrapa Agroindústria Tropical. Fortaleza-CE. Brasil.

${ }^{5}$ Embrapa Algodão. Campina Grande-PB. Brasil.

\section{PaLAVRAS ChaVE ADICIONAIS}

Co-produto. Fibra. Lactação. Pequenos ruminantes. Ricinus communis.

\section{RESUMO}

Objetivou-se com o presente trabalho, avaliar o efeito dos níveis de substituição do feno de capim Tifton 85 pela casca de mamona na dieta de cabras sobre a produção, composição química e perfil de ácidos graxos do leite. Foram utilizadas 8 fêmeas caprinas Anglo-Nubianas, com peso médio de $45 \mathrm{~kg}$. Os animais foram alojados em baias e distribuídos em delineamento em quadrado latino $4 \times 4$ duplo. Os tratamentos consistiram de três níveis de substituição do feno de capim Tifton 85 pela casca de mamona como alimento volumoso $(0,33,67$ e 100\%) mantendo a relação volumoso:concentrado de 50:50. Cada período experimental teve duração de 21 dias, sendo 14 dias de adaptação e sete dias de coleta de dados. Houve um decréscimo na produção quando a casca de mamona foi inclusa na dieta, sendo que os últimos dois níveis não diferiram entre si. Em relação à composição química do leite, não houve efeito da substituição do feno de capim Tifton 85 pela casca de mamona sobre os teores de proteína bruta, matéria mineral, lactose e extrato seco total. Houve aumento do teor de gordura do leite nos níveis 67 e 100\% de substituição, porém isso não causou variação na densidade do leite, cuja

*Projeto financiado pela Embrapa-parte da dissertação da primeira autora.

Recibido: 9-9-08. Aceptado: 22-7-09.

\section{Additional KeYWORDS}

Byproduct. Fiber. Small ruminant. Ricinus communis.

média foi de 1031. Quanto ao efeito da substituição do feno de capim Tifton 85 pela casca de mamona sobre a concentração dos ácidos graxos, houve efeito sobre os teores dos ácidos mirístico $\left(C_{14: 0}\right)$, linoelaidico $\left(\mathrm{C}_{18: 2 n 6 t}\right)$, linoléico conjugado ( $\left.\mathrm{CLA}_{9 \mathrm{t} 11}\right)$ e para o perfil de ácidos graxos saturados (AGSAT), poliinsaturados (AGPOL) e essenciais (AGESS) $(p<0,05)$. Não houve efeito dos tratamentos sobre ácidos graxos insaturados, de cadeia curta, de cadeia longa e monoinsaturados $(p>0,05)$. A substituição do feno de capim Tifton 85 pela casca de mamona reduziu o índice de aterogenicidade (IA) da dieta. De acordo com os resultados obtidos pode-se considerar que a substituição do feno de capim Tifton 85 pela casca de mamona em até $33 \%$, é viável quando o objetivo for melhorar os aspectos qualitativos do leite de cabra.

\section{SUMMARY}

The aim of this work was to evaluate the effect of substitution levels of the Tifton 85 hay by castor bean hulls in diets for dairy goats on the yield, chemical composition and fatty acids profile of milk. Eight Anglo-Nubian female goats, breed, with average weight of $45 \mathrm{~kg}$ were used. The animals were allocated in stalls and distributed in a double

Arch. Zootec. 60 (229): 113-122. 2011. 
$4 \times 4$ latin square experimental design. The treatments consisted of three levels of substitution of the Tifton 85 hay by castor bean hulls as roughage food $(0,33,67$ and $100 \%)$ maintaining the roughage:concentrate ratio of 50:50. Each experimental period had a duration of 21 days, being 14 days of adaptation and seven days of data collection. There was a decrease in production when the castor hulls were included in diet, and two diets containing the highest levels of inclusion of the castor bean hulls did not differ between themselves. For milk chemical composition, there was no effect when Tifton 85 hay was substituted by castor bean hulls on the crude protein, minerals, lactose and total dry extract. The fat milk level was increased when the castor bean hulls substituted the Tifton 85 hay in the levels 67 and $100 \%$, but it caused no change in milk density, whose average density was 1031 . The substitution of Tifton 85 hay by castor bean hulls promoted effect on the fatty acids concentration. Was found significant effect, for fatty acid concentration, on the levels of miristic acid $\left(C_{14: 0}\right)$, linoelaidic acid $\left(C_{18: 2 n 6 t}\right)$, conjugated linoleic acid (CLA $\left.{ }_{9 t 11}\right)$ and on the profile of saturated (AGSAT), polyunsaturated (AGPOL) and essential fatty acids (AGESS) $(p<0.05)$. There was no effect of treatments on unsaturated, short chain, long chain and monounsaturated fatty acids $(p>0.05)$. The substitution of Tifton 85 hay by castor bean hulls reduced the atherogenicity index (AI) of the diet. The castor bean hulls can replace the Tifton 85 hay in up to $33 \%$ in diet of dairy goats. This substitution can be viable when the goal is to have goat milk with better nutritional characteristics.

\section{INTRODUÇÃO}

O leite é considerado um dos alimentos mais completos por constituir-se de diversos nutrientes que apresentam importância para a nutrição humana. O valor nutricional do leite de cabra é bastante conhecido e sua utilização tem sido uma ótima alternativa alimentar para crianças e adultos alérgicos ao leite de vaca (Mesquita et al., 2004). Segundo Chapaval et al. (2006) e Mendes et al. (2007), a preferência do leite de cabra pelos consumidores é atribuída as suas características nutricionais e sua alta digestibilidade.

No Brasil, a produção de leite de cabra tem sido importante ferramenta de inclusão de pequenos produtores no mercado, seja institucional (venda para o governo), seja formal (laticínios privados). Em busca de melhor produtividade, estão sendo utilizados animais com maior potencial genético para produção. Entretanto, estes animais exigem um maior aporte de nutrientes pela maior exigência nutricional o que pode em alguns casos inviabilizar economicamente a produção.

Atualmente, há um grande incentivo governamental para a produção de biodiesel a partir da mamona, especialmente no nordeste brasileiro. Este aumento na produção de mamona para a indústria irá gerar diferentes co-produtos, alguns dos quais com potencial para utilização na alimentação animal. Dentre estes está à casca de mamona, Suas informações referentes ao valor nutritivo na alimentação de ruminantes é escassa na literatura e representa uma demanda real da cadeia produtiva. Portanto, objetivou-se, com o presente estudo avaliar o efeito da substituição do feno de capim Tifton 85 pela casca de mamona em diferentes níveis sobre a produção, composição e o perfil de ácidos graxos do leite de cabras leiteiras.

\section{MATERIAL E MÉTODOS}

O experimento foi conduzido na Embrapa Caprinos em Sobral-CE. Foram utilizadas oito fêmeas caprinas leiteiras da raça anglonubiano, com peso vivo médio inicial de 45 $\mathrm{kg}$. Os animais foram mantidos em baias e distribuídos em delineamento em quadrado latino $4 \times 4$ duplo, para avaliar o efeito nutricional da casca de mamona em substituição ao feno de capim Tifton 85 , em dietas isoprotéicas e isoenergéticas, respeitando a relação volumoso:concentrado de 50:50 em todos os tratamentos (tabela I). A casca de mamona utilizada no experimento apresentava $6 \%$ de fragmentos de sementes, o que conferiu a este alimento fibroso $2,5 \%$ de extrato etéreo. Cada perío- 


\section{EFEITO DA CASCA DE MAMONA EM LEITE DE CABRA}

do experimental teve duração de 21 dias, sendo 14 dias de adaptação a dietas e sete dias de coleta de dados, totalizando 84 dias de período experimental. Os acessos às dietas, água e sal mineral foram ad libitum. $\mathrm{O}$ fornecimento das dietas foi dividido em duas refeições diárias, garantindo sobras de $10 \%$ a $15 \%$ do total oferecido. A determinação da composição químico bromatológica das dietas foi feita no Laboratório de Nutrição Animal da Embrapa-Caprinos. Os teores de MS, nitrogênio total, EE, FDN, Ca e P foram determinados segundo metodologias descritas em Association of Official Analytical Chemists (AOAC, 1980). O teor de proteína bruta das dietas foi estimado multiplicandose seu teor de nitrogênio total por 6,25 . A energia metabolizável das dietas foi estimada segundo Agricultural Food Research Council (AFRC, 1993). Para mensuração da produção de leite as cabras foram ordenhadas manualmente duas vezes ao dia e tiveram a produção registrada diariamente durante os sete dias de coleta usando balança eletrônica. Durante três dias do período experimental, o leite foi amostrado proporcionalmente às ordenhas da manhã e da tarde. Estas amostras foram utilizadas para a determinação da composição em gordura, proteína, minerais e densidade, seguindo as técnicas descrita em Association of Official Analytical Chemists (AOAC, 1980). O leite foi corrigido para o teor de $4 \%$ de gordura (PLC4\%), conforme a fórmula citada pelo

Tabela I. Proporção, composição bromatológica expressa em base de matéria e composição percentual do total de ácidos graxos dos alimentos utilizados na formulação das dietas experimentais. (Percentage of inclusion and chemical composition of each food, expressed as dry matter basis, and percentage of fatty acids, expressed in $\%$ of total fatty acid, of the experimental diets).

\begin{tabular}{lcccc}
\hline & $0 \%$ & $33 \%$ & $67 \%$ & $100 \%$ \\
\hline Feno de capim Tifton 85 & 50,21 & 32,24 & 16,14 & - \\
Casca de mamona & 0,00 & 15,93 & 32,65 & 48,17 \\
Milho & 42,83 & 44,05 & 39,77 & 38,50 \\
Farelo de soja & 6,19 & 7,10 & 9,35 & 10,52 \\
Fosfato bicálcio & 0,14 & 0,00 & 0,00 & 0,00 \\
Calcário & 0,63 & 0,68 & 0,65 & 0,60 \\
Óleo de soja & 0,00 & 0,00 & 1,45 & 2,21 \\
Relação vol:conc & $50: 50$ & $50: 50$ & $50: 50$ & $50: 50$ \\
Composição bromatológica (\%MS) & & & & \\
Matéria seca (MS) & 82,3 & 84,4 & 85,0 & 84,0 \\
Proteína bruta (PB) & 11,99 & 11,84 & 11,96 & 11,84 \\
Extrato etéreo (EE) & 4,09 & 4,11 & 3,86 & 3,77 \\
Fibra em detergente neutro (FDN) & 43,57 & 41,70 & 41,91 & 41,13 \\
Energia metabolizável (EM) (Mcal/d) & 2,52 & 2,52 & 2,52 & 2,52 \\
Cálcio (Ca) & 0,54 & 0,54 & 0,54 & 0,54 \\
Fósforo (P) & 0,255 & 0,255 & 0,255 & 0,255 \\
Composição em ácidos graxos (\%) & & & & \\
Palmítico(C16:0) & 11,45 & 12,5 & 12,22 & 12,70 \\
Esteárico (C18:0) & 3,07 & 3,05 & 3,32 & 3,42 \\
Oléico (C18:1n 9c) & 18,05 & 19,84 & 19,79 & 21,15 \\
Linoléico (C18:2n 6c) & 32,82 & 35,84 & 37,99 & 40,05 \\
$\gamma$-Linolênico (C18:3n6) & - & 0,57 & 1,18 & 1,75 \\
Linolênico (C18:3n3) & 17,96 & 11,93 & 7,24 & 1,93 \\
Ricinoléico (C18:1-OH) & - & 6,25 & 12,85 & 18,94 \\
\hline
\end{tabular}


Nutrient Requirements of Dairy Cattle(NRC, 1989):

PLC 4\%=PL $\times[0,4+(\%$ G leite $\times 0,15)]$,

onde:

$\mathrm{PL}$ é a produção de leite,

$G$ é a gordura do leite.

A lactose foi estimada pela diferença entre os percentuais de matéria seca, proteína bruta, matéria mineral e gordura do leite,

$$
L=M S \%-(M M \%+P B \%+G \%)
$$

Para determinação do perfil de ácidos graxos, após a amostragem uma alíquota foi imediatamente congelada em garrafas plásticas, efetuando-se posteriormente a extração da gordura, conforme metodologia descrita por Feng et al. (2004). Alíquotas de $30 \mathrm{ml}$ foram centrifugadas a $17800 \mathrm{x} g$ por 30 minutos a $4^{\circ} \mathrm{C}$ (IEC B-22M) formando um creme de leite na camada superior (fat cake), o qual foi retirado, ainda congelado, com auxílio de palhetas plásticas. Aproximadamente $1 \mathrm{~g}$ do (fat cake) foi transferido para tubos eppendorf de 1,5 ml, e centrifugado a $19.300 \mathrm{x}$ g por 20 minutos em temperatura ambiente (5415 R) para obtenção da fração lipídica que permaneceu na parte superior. Essa fração foi retirada e transferida, com auxílio de micropipetas, para um novo eppendorf e armazenadas $\mathrm{a}-10^{\circ} \mathrm{C}$ até a etapa de preparação dos ésteres metílicos.

A preparação dos ésteres metílicos foi realizada por meio da modificação do método proposto por Hartman e Lago (1986). Alíquotas de $40 \mu \mathrm{l}$ da gordura foram transferidas para tubos de ensaio com tampa rosqueada. Os lipídios foram hidrolisados com adição de 2,5 ml de solução de $\mathrm{NaOH} 0,5$ $\mathrm{N}$ em metanol sob aquecimento a $70^{\circ} \mathrm{C}$ por 15 minutos, para completa saponificação da amostra e obtenção de ácidos graxos livres. Após resfriamento, foram adicionados 7,5 $\mathrm{ml}$ de reagente de esterificação $(\mathrm{HCl} 0,5 \mathrm{~N}$ em metanol), aquecendo-se a $70^{\circ} \mathrm{C}$ por 10 minutos para formação dos ésteres metílicos. Após resfriamento, acrescentaram-se $2 \mathrm{ml}$ de solução de $\mathrm{NaCl} 20 \%$ e $2 \mathrm{ml}$ de hexano (grau HPLC). O tubo foi agitado em vortex e aproximadamente $1 \mathrm{ml}$ da fase superior contendo os ésteres metílicos foi coletado. Adicionou-se mais $1 \mathrm{ml}$ de hexano (grau HPLC), coletando-se novamente $1 \mathrm{ml} \mathrm{da}$ fase superior. Os ésteres metílicos foram acondicionados em frascos de vidro da cor âmbar e estocados a $-18^{\circ} \mathrm{C}$, para a análise. As análises dos ésteres metílicos dos ácidos graxos da gordura do leite foram realizadas no Laboratório de Análises Instrumental da Embrapa Agroindústria Tropical, em cromatógrafo a gás modelo VARIAN CP3380, equipado com detector de ionização de chamas (FID), por meio da modificação do método proposto por Chilliard et al. (2006). Para registrar e analisar os cromatogramas, o aparelho foi acoplado a um microcomputador, utilizando-se o programa Varian Star Chromatography Workstation. Os componentes dos ésteres metílicos foram separados em coluna capilar SP-2560 (100 m x 0,25 mm x 0,02 $\mu \mathrm{m}$; Supelco).

Para a separação cromatográfica, $1 \mu l$ da amostra foi injetado com o auxílio de uma seringa de $10 \mu 1$, em sistema split com razão 1:100. O hidrogênio foi utilizado como gás carreador e como make-up, em ambos os casos com vazão regulada para $30 \mathrm{ml} / \mathrm{min}$. A vazão do ar sintético foi mantida em $300 \mathrm{ml} /$ min e as temperaturas do injetor e do detector em torno de $255^{\circ} \mathrm{C}$. A temperatura inicial do forno foi de $70^{\circ} \mathrm{C}$, aumentando gradativamente até $240^{\circ} \mathrm{C}$, permanecendo nessa temperatura por 83 minutos, período este, estipulado para a realização da análise. $\mathrm{O}$ pico de cada ácido graxo foi identificado comparando-se com o tempo de retenção dos picos presentes no padrão de lipídios, composto por mistura de ácidos graxos (Supelco 37 - Component FAME Mix - $10000 \mathrm{mg}$ in $\mathrm{CH}_{2} \mathrm{Cl}_{2} / \mathrm{SUPELCO}$ cat. 47885-U; ricinoleato de metilo puriss. p.a., padrão para CG, $\geq 99,0 \%$, GC-FLUKA cat. 83916; e acido linoléico conjugado ester 


\section{EFEITO DA CASCA DE MAMONA EM LEITE DE CABRA}

metilico/SIGMA cat. O5632).

Os dados foram analisados por meio de análise de regressão. A escolha do modelo baseou-se na significância dos coeficientes linear. A análise estatística dos dados foi feita com o auxílio do Software Sistema de Análises Estatísticas e Genéticas (SAEG, 2007) e os efeitos dos tratamentos, avaliados ao nível de 0,05 de significância.

\section{RESULTADOEDISCUSSÃO}

Como pode ser observado (tabela II), houve efeito dos tratamentos sobre a produção de leite $(\mathrm{p}<0,01)$, o teor de gordura $(p<0,01)$ e a densidade do leite $(p<0,05)$. A produção de leite e a concentração de gordura dos animais que receberam dietas com substituição de $33 \%$ do feno de capim-tifon 85 pela casca de mamona não foi diferente daqueles que receberam $100 \%$ de feno de capim Tifton 85 como fonte de volumoso. No entanto, com $67 \%$ e $100 \%$ de substituição observou-se uma redução significativa da produção, cerca de 0,0031 pontos percentuais (p.p.) para cada $1 \%$ de substituição, sendo que entre estes dois níveis não houve diferença. Este comportamento da produção do leite pode estar relacionado ao nível e tipo de óleo presente nas dietas, uma vez que, com os níveis crescentes de substituição elevou-se o teor de ácido ricinoléico das dietas (tabela I), que além de reduzir o consumo e a digestibilidade também ocasiona redução na produção animal (Bomfim et al., 2006, Eifert et al., 2006).

Não houve efeito dos tratamentos para os teores de proteína bruta do leite, matéria mineral, lactose e extrato seco total com médias de 3,99; 0,88; 3,73 e 12,75\%, respectivamente (tabela II). Para o teor de gordura láctea, os resultados apresentaram um aumento linear de 0,01 p.p. para cada nível de substituição $(\mathrm{p}<0,01)$. Dois aspectos podem ter contribuído para isto. Primeiro, a redução na produção de leite, que pode ter tornado o leite mais concentrado e segundo, a presença de óleo nas dietas com aumento dos níveis de substituição (tabela II), que reconhecidamente pode aumentar o teor de gordura no leite de cabra (Chilliard et al., 2003). A resposta à presença de óleo na dieta difere consideravelmente entre cabras (Chilliard e Bocquier, 1993), vacas leiteiras (Chilliard et al., 2001) e ovelhas (Nudda et al., 2002). Segundo esses autores, a

Tabela II. Efeito do nível de substituição do feno de capim Tifton pela casca de mamona sobre a produção de leite $(P L)$ e os teores de proteina bruta $(P B)$, de gordura $(G)$, de matéria mineral (MM), de lactose (LAC), a densidade (D) e o extrato seco total (EST) por cabras lactantes. (Effect of replacement level of Tifton hay by castor bean hulls on milk yield (PL), crude protein $(P B)$, fat (G), mineral matter (MM) and lactose (LAC) levels, density (D) and total solids (EST), in lactating goats).

\begin{tabular}{|c|c|c|c|c|c|c|c|}
\hline \multirow[t]{2}{*}{ Variáveis } & \multirow[b]{2}{*}{$0 \%$} & \multicolumn{3}{|c|}{ Níveis de casca } & \multirow[t]{2}{*}{ Equação estimada } & \multirow[t]{2}{*}{$\mathrm{R}^{2}$} & \multirow[t]{2}{*}{ CV (\%) } \\
\hline & & $33 \%$ & $67 \%$ & $100 \%$ & & & \\
\hline$P L(g / d)$ & 1,050 & 0,933 & 0,743 & 0,767 & $Y=1,028-0,0031 x^{* *}$ & 0,86 & 13,22 \\
\hline PBL (\%) & 3,92 & 3,89 & 3,92 & 4,25 & $Y=3,99$ & - & 13,75 \\
\hline GL (\%) & 3,67 & 3,97 & 4,21 & 4,71 & $Y=3,64+0,010 x^{* *}$ & 0,97 & 11,55 \\
\hline MM (\%) & 0,88 & 0,90 & 0,92 & 0,85 & $Y=0,88$ & - & 10,30 \\
\hline LAC (\%) & 3,67 & 3,84 & 4,29 & 3,12 & $Y=3,73$ & - & 26,74 \\
\hline $\mathrm{D}\left(\mathrm{g} / \mathrm{cm}^{3}\right)$ & 1032 & 1031 & 1031 & 1032 & $Y=1032,19-0,025 x+0,00025 x^{2 *}$ & 0,83 & 0,053 \\
\hline EST (\%) & 12,13 & 12,59 & 12,33 & 12,92 & $Y=12,75$ & - & 7,18 \\
\hline
\end{tabular}

${ }^{*} p<0,05 ;{ }^{* *} p<0,01 ; C V=$ Coeficiente de variação. 
produção de leite no meio da lactação normalmente aumenta em vacas, mas não em cabras e ovelhas; a concentração de gordura do leite aumenta em cabras e ovelhas, porém pode não alterar em vacas; o teor de proteína bruta do leite diminui em vacas e ovelhas, mas se altera em cabras; Portanto, os dados aqui encontrados neste trabalho corroboram com os descritos por esses autores.

Não houve efeito dos tratamentos sobre a concentração de vário ácidos graxos, dentre eles estão o butírico $\left(\mathrm{C}_{4: 0}\right)$, capróico $\left(\mathrm{C}_{6: 0}\right)$, caprílico $\left(\mathrm{C}_{8: 0}\right)$, com média de 0,79 ; 1,55 e $1,75 \%$ respectivamente. Estes valores ficaram próximos dos encontrado por Maia et al. (2006), utilizando diferentes fontes de óleo na dieta de cabras Saanen em lactação sobre a produção e composição do leite e perfil de ácidos graxos do leite.

Observou-se um aumento na concentração do ácido cáprico $\left(\mathrm{C}_{10: 0}\right)$, quando comparados os níveis de substituição de 33 e $67 \%$ do feno de capim Tifton 85 pela casca de mamona. $\mathrm{O}$ aumento foi de 0,34 p.p. para cada $1 \%$ de substituição. Os valores obtidos ficaram próximos dos encontrados por Koning e Schaafsma (1997), Alonso et al. (1999) e Queiroga e Costa (2003).

A percentagem na concentração do ácido mirístico $\left(\mathrm{C}_{14: 0}\right)$, apresentou um comportamento quadrático (tabela III), demonstrando significância aos tratamentos $(\mathrm{p}<0,05)$, com diminuição de 0,36 p.p. para cada $1 \%$ de substituição. O coeficiente do ácido linoléico $\left(\mathrm{C}_{18: 2 n 6 \mathrm{c}}\right)$, também apresentou comportamento quadrático, com significância de $(\mathrm{p}<0,05)$, como mostra a (tabela III), sendo que a diminuição ocorreu no nível de $33 \%$ de participação da casca, tendo aumento nos níveis 67 e $100 \%$.

Para o ácido linoléico conjugado (CLA 9 t11), observou-se aumento de $0,561 \%$ para cada $1 \%$ de participação da casca. O aumento no teor de CLA pode ter ocorrido devido à presença de óleos adicionados nas dietas, decorrente do aumento nos níveis de substituição, uma vez que à medida que se aumentou o nível de participação da casca de mamona, também elevou-se a presença do óleo ricinoléico (devido a presença de sementes de mamona na casca), assim como também a concentração do óleo de soja (tabela I), que segundo (Silva, 2005), apresenta um percentual de 55,54 do ácido linoléico, que é um dos precursores do CLA.

É importante ressaltar que a presença de óleo propicia o ataque dos microrganismos sobre estas fontes de energia de forma mais efetiva, favorecendo o processo de biohidrogenação (Maia et al., 2006). O aumento do teor de CLA está relacionado com o aumento da gordura do leite. Uma vez que o CLA presente na gordura do leite é proveniente em parte da biohidrogenação ruminal do $\mathrm{C}_{18: 2 n-6}$ e parte resultante da atividade da enzima $\Delta-9$ desaturase nas células da glândula mamária, que transformam o ácido vacênico $\left(\mathrm{C}_{18 \text {.1n-7 }}\right)$ absorvido da corrente sangüínea em CLA (Bauman e Griinari, 2001), esperando, portanto, que quanto maior a concentração de linoléico na dieta (tabela II), maiores as chances de incrementar o CLA na gordura do leite.

Segundo Cook et al. (1993), Nicolosi et al. (1993) e Parodi (2003), este aumento no perfil de CLA é muito importante, uma vez que esta classe de isômeros do ácido linoléico (C18:2) é hoje reconhecida como tendo propriedades anticarcinogênicas, antiaterogênica, antioxidante e imunomoduladora em estudos feitos com animais. Não houve efeito dos tratamentos sobre o teor de ácido graxo ricinoléico $(\mathrm{C} 18 ; 1 \mathrm{OH})$ na gordura do leite. Apenas os tratamentos com 67 e 100\% de substituição exibiram traços destes ácidos graxos que podem estar implicados em efeito laxativo do óleo de mamona.

Para o perfil dos AGSAT (tabela IV), os resultados obtidos se comportaram de forma quadrática, notando-se um aumento no nível de 33\% de substituição. Deste ponto em diante, houve uma redução nos valores observados de $-1,64$ para cada $1 \%$ de substituição. 


\section{EFEITO DA CASCA DE MAMONA EM LEITE DE CABRA}

Embora o teor de AGSAT tenha reduzido, não houve efeito dos tratamentos sobre os teores de AGINS AGCC, AGCL E MONO, com média de 22,41; 19,19; 30,69 e 17, 82 respectivamente. Contudo, para o perfil de AGPOL e AGESS, observou-se influência pelos tratamentos. Com o aumento no nível de substituição, houve aumento no teor de

Tabela III. Efeito do nível de substituição do feno de capim Tifton pela casca de mamona sobre a composição percentual dos ácidos graxos na gordura do leite de cabras lactantes. (Effect of replacement level of Tifton hay by castor bean hulls on percentage composition of fatty acids in milk fat of lactating goats).

\begin{tabular}{|c|c|c|c|c|c|c|c|c|}
\hline \multirow{2}{*}{$\begin{array}{l}\text { Ácidos } \\
\text { graxos }\end{array}$} & \multirow[b]{2}{*}{ Denominação } & \multicolumn{4}{|c|}{ Níveis de substituição } & \multirow[t]{2}{*}{ Equação estimada } & \multirow[t]{2}{*}{$\mathrm{R}^{2}$} & \multirow[t]{2}{*}{ CV (\%) } \\
\hline & & $0 \%$ & $33 \%$ & $67 \%$ & $100 \%$ & & & \\
\hline C4:0 & Butírico & 0,84 & 0,83 & 0,75 & 0,73 & $Y=0,79$ & - & 26,86 \\
\hline C6:0 & Capróico & 1,52 & 1,54 & 1,53 & 1,61 & $Y=1,55$ & - & 16,72 \\
\hline C8:0 & Caprílico & 1,60 & 1,70 & 1,80 & 1,90 & $Y=1,75$ & - & 13,77 \\
\hline C10:0 & Cáprico & 8,55 & 9,11 & 9,74 & 9,50 & $Y=8,36+0,343 x^{*}$ & 0,77 & 7,02 \\
\hline C11:0 & Undecanóico & 0,13 & 0,13 & 0,19 & 0,17 & $Y=0,15$ & - & 40,46 \\
\hline C12:0 & Láurico & 5,41 & 5,56 & 5,90 & 4,95 & $Y=5,45$ & - & 11,86 \\
\hline C13:0 & Tridecanóico & 0,30 & 0,24 & 0,33 & 0,30 & $Y=0,30$ & - & 26,34 \\
\hline C14:0 & Mirístico & 9,06 & 9,01 & 8,98 & 7,41 & $Y=7,99+1,35 x-0,36 x^{2 *}$ & 0,92 & 7,91 \\
\hline C14:1 & Mirístoleico & 0,20 & 0,21 & 0,21 & 0,15 & $Y=0,20$ & - & 24,12 \\
\hline C15:0 & Pentadecanóico & 1,15 & 1,07 & 1,12 & 0,90 & $Y=1,06$ & - & 15,68 \\
\hline \multirow[t]{2}{*}{ C15:1 } & Cis- 10- & & & & & & & \\
\hline & Pentadecanóico & 0,23 & 0,35 & 0,44 & 0,12 & $Y=0,30$ & - & 238,0 \\
\hline C16:0 & Palmítico & 20,18 & 20,11 & 19,23 & 17,73 & $Y=19,31$ & - & 7,51 \\
\hline C16:1 & Palmitoléico & 0,68 & 0,63 & 0,82 & 0,69 & $Y=0,70$ & - & 28,73 \\
\hline C17:0 & Heptadecanóico & 0,85 & 0,77 & 0,76 & 0,67 & $Y=0,76$ & - & 24,23 \\
\hline \multirow[t]{2}{*}{ C17:1 } & Cis-10- & & & & & & & \\
\hline & Heptadecanóico & 0,50 & 0,10 & 0,60 & 0,69 & $Y=0,47$ & - & 104,0 \\
\hline C18:0 & Esteárico & 8,72 & 8,91 & 7,57 & 7,48 & $Y=8,17$ & - & 21,50 \\
\hline C18:1n 9t & Elaidico & 0,18 & 0,21 & 0,27 & 0,43 & $Y=0,27$ & - & 21,03 \\
\hline C18:1n 9c & Oleico & 18,80 & 17,94 & 17,45 & 17,12 & $Y=17,82$ & - & 8,90 \\
\hline C18:2n 6t & Linoelaídico & 0,22 & 0,14 & 0,19 & 0,13 & $Y=8,39+0,73 x-0,303 x^{2 *}$ & 0,95 & 94,09 \\
\hline C18:2n 6c & Linoléico & 1,80 & 1,65 & 1,86 & 2,64 & $Y=2,56-1,02 x+0,271 x^{2 *}$ & 0,99 & 14,71 \\
\hline C20:0 & Arquídico & 0,24 & 0,28 & 0,21 & 0,22 & $Y=0,23$ & - & 181,04 \\
\hline C18:3n6 & $\gamma$-Linolênico & 0,20 & 0,18 & 0,19 & 0,61 & $Y=0,30$ & - & 8,87 \\
\hline \multirow[t]{2}{*}{ C20:1 } & Cis - 11 - & & & & & & & \\
\hline & Eicosenóico & 0,33 & 0,19 & 0,32 & 0,50 & $Y=0,33$ & - & 264,13 \\
\hline C18:3n3 & Linolênico & 0,24 & 0,21 & 0,15 & 0,19 & $Y=0,19$ & - & 29,60 \\
\hline \multirow[t]{2}{*}{ CLA9t11 } & $\begin{array}{l}\text { Ácido linoléico } \\
\text { conjugado cis-9 }\end{array}$ & & & & & & & \\
\hline & trans 11 & 0,34 & 0,43 & 0,78 & 1,84 & $Y=0,50+0,561 x^{* *}$ & 0,76 & 84,67 \\
\hline C21:0 & Heneicosanóico & 0,32 & 0,29 & 0,28 & 0,25 & $Y=0,30$ & - & 41,10 \\
\hline \multirow[t]{2}{*}{ C20:2 } & Cis - 11, 14 - & & & & & & & \\
\hline & Eicosadienóico & 0,50 & 0,59 & 0,11 & 0,13 & $Y=0,33$ & - & 136,11 \\
\hline $\mathrm{C} 22: 0$ & Behênico & 0,40 & 0,40 & 0,31 & 0,27 & $Y=0,34$ & - & 52,28 \\
\hline C18:1OH & Ácido ricinoléico & 0,00 & 0,00 & 0,71 & 0,87 & $Y=0,40$ & - & 265,89 \\
\hline $\mathrm{NI}$ & Não identificados & 20,27 & 19,02 & 19,87 & 22,87 & $Y=20,50$ & - & 10,44 \\
\hline
\end{tabular}

${ }^{*} p<0,05 ;{ }^{* *} p<0,01 ; C V=$ Coeficiente de variação. 
Tabela IV. Perfil de ácidos graxos em cabras lactantes alimentadas com dietas contendo quatro níveis de substituição do feno de capim Tifton 85 pela casca de mamona (\% do total de $A G$ ). (Fatty acid profile in lactating goats fed diets containing four replacement levels of Tifton 85 hay by castor bean hulls ( $\%$ of total fatty acids)).

\begin{tabular}{lccccccc}
\hline \multirow{2}{*}{ Variáveis } & \multicolumn{3}{c}{ Nível de substituição } & Equação estimada & $R^{2}$ & CV (\%) \\
& $0 \%$ & $33 \%$ & $67 \%$ & $100 \%$ & & \\
\hline AGSAT & 58,61 & 59,31 & 58,18 & 53,56 & $Y=53,84+6,26 x-1,64 x^{2 *}$ & 0,98 & 3,61 \\
AGINS & 22,57 & 21,63 & 21,91 & 23,53 & $Y=22,41$ & - & 6,92 \\
AGPOL & 2,62 & 2,47 & 3,01 & 4,87 & $Y=4,40-2,35 x+0,647 x^{*}$ & 0,98 & 30,69 \\
Rel Sat/Ins & 2,60 & 2,75 & 2,67 & 2,27 & $Y=2,170,571 x-0,13 x^{2 *}$ & 0,99 & 8,92 \\
RelPol/Ins & 0,11 & 0,11 & 0,13 & 0,20 & $Y=0,180-8,66 x+2,46 x^{2 *}$ & 0,98 & 28,19 \\
AGESS & 1,81 & 1,67 & 1,88 & 2,70 & $Y=2,63-1,07 x+0,285 x^{2 *}$ & 0,99 & 14,21 \\
AGCC & 18,34 & 19,10 & 20,25 & 19,10 & $Y=19,19$ & - & 6,63 \\
AGCM & 31,31 & 31,09 & 30,42 & 27,03 & $Y=33,49-1,42 x^{*}$ & 0,72 & 7,34 \\
AGCL & 31,56 & 30,78 & 29,45 & 30,98 & $Y=30,69$ & - & 9,57 \\
MONO & 18,80 & 17,94 & 17,45 & 17,12 & $Y=17,82$ & - & 9,29 \\
T18:1 & 0,18 & 0,21 & 0,27 & 0,43 & $Y=0,281-0,136 x+4,44 x^{2 *}$ & 0,97 & 19,49 \\
IA & 2,75 & 2,86 & 2,80 & 2,22 & $Y=2,24+0,658 x-0,164 x^{2 *}$ & 0,98 & 13,71 \\
\hline
\end{tabular}

${ }^{*} p<0,05 ;{ }^{* *} p<0,01 ; C V=$ Coeficiente de variação.

AGSAT = Ácidos graxos saturados; AGINS= Ácidos graxos insaturados; AGPOL= Ácidos graxos poliinsaturados; Rel Sat/Ins= Relação total de ácidos graxos saturados: total de insaturados; Rel Poli/ Ins= Relação total ácidos graxos poliinsaturados:total de insaturados; AGESS= Ácidos graxos essenciais ( $\Sigma$ C18:2; C18:3); AGCC= Ácidos graxos cadeia curta ( $\Sigma$ C4:C13); AGCM = Ácidos graxos de cadeia média ( $\Sigma$ C14:C16); $A G C L=$ Ácidos graxos de cadeia longa ( $\Sigma>C 16)$; MONO= Total de ácidos graxos monoinsaturados; T18:1= Total de ácidos graxos C18:1 -Trans; IA= Índice de aterogenicidade $[\{\mathrm{C} 12: 0+(4 \times \mathrm{C} 14: 0)+\mathrm{C} 16\} /$ Total insaturados $]$.

ácidos graxos de mais de uma saturação de $0,647 \%$ e de ácidos graxos essenciais de $0,285 \%$ para cada nível de substituição.

Estes aumentos nos perfis de AGPOL e AGESS, estão relacionados com o aumento no perfil de dos ácidos linoléico $\left(\mathrm{C}_{18: 2 n 6 c}\right) \mathrm{e}$ ácido linoléico conjugado cis-9 trans 11 $\left(\mathrm{CLA}_{9+11}\right)$, (tabela III) Estes resultados fizeram com que as relações saturado:insaturado e a relação poliinsaturado:insaturado fossem mais favoráveis, especialmente no último nível de substituição.

O teor dos AGCM reduziu linearmente à medida que se aumentou o nível de substituição. Este resultado é conseqüência da diminuição do perfil dos ácidos mirístico $\left(\mathrm{C}_{14 \cdot 0}\right)$ e palmítico $\left(\mathrm{C}_{16: 0}\right)$, (tabela III).

O teor dos ácidos graxos trans comportou-se de maneira quadrática. Com aumento nos níveis de casca, especialmente nos níveis de 67 e 100\% de substituição. Estes ácidos graxos são resultantes da reação de isomerização da biohidrogenação, na qual converte a dupla ligação cis 12 no ácido graxo poliinsaturado para seu isômero trans 11 .

Menor índice de aterogenicidade (IA) foi obtido com o nível $100 \%$ de substituição indicando que, no que se refere ao potencial da gordura em gerar colesterol endógeno, houve melhora na qualidade com o aumento dos níveis.

\section{CONCLUSÕES}

Em relação à produção de leite, pode-se considerar que o melhor nível de substituição do feno de capim Tifton 85 pela casca de mamona é do de $33 \%$, quando o objetivo 


\section{EFEITO DA CASCA DE MAMONA EM LEITE DE CABRA}

for melhorar a produção. E em relação a composição e perfil de ácidos graxos, o melhor nível de substituição a ser considerado é o de $100 \%$, quando o objetivo for

\section{BIBLIOGRAFIA}

AFRC. 1993. Agricultural and Food Research Council. Energy and protein requirements of ruminants. CAB International. Wallingford. Oxon OX10 8DE. UK. 175 pp.

Alonso, L., Fontecha, J., Lozada, L., Fraga, M.J. and Juárez, M. 1999. Fatty acid composition of caprine milk: major, branched-chain and trans fatty acids. J. Dairy Sci., 82: 878-884.

AOAC. 1980. Association of Official Analytical Chemists. Official methods of analysis. $13^{\text {th }} \mathrm{ed}$ Washington, DC. 1094 pp.

Bauman, D.E. and Griinari, J.M. 2001. Regulation and nutritional manipulation of milk fat low-fat milk síndrome. Livest. Prod. Sci., 70: 15-29.

Bomfim, M.A.D., Severino, L.S., Cavalcante, A.C.R., Oliveira, A., Gomes, G.M.F., Pereira, L.P.S. e Oliveira, S.Z.R. 2006. Avaliação da casca de mamona na dieta de ovinos. Em: IV Congresso Nordestino de Produção Animal. Petrolina, PE. pp. 936-939.

Chapaval, L., Oliveira, A.A.F., Alves, F.S.F., Andrioli, A., Araújo, A.M. e Olvindo, C.S. 2006. Manual do produtor de cabras leiteiras. Aprenda Fácil. Viçosa, MG. 214 pp.

Chilliard, Y. and Bocquier, F. 1993. Effects of fat supplementation on milk yield and composition in dairy goats and ewes. In: International Symposium la Qualita nell Produzioni dei Piccoli Ruminanti, 5. 1993, Varese. Proceedings. Camera di Commercio Industria Artigianato Agricultura di Varese. Varese. pp. 61-78.

Chilliard, Y., Ferlay, A. et Doreau, M. 2001. Contrôle de la qualité nutritionnelle des matières grasses du lait par l'alimentation des vaches laitières: acides gras trans, polyinsaturés, acide linoléique conjugué. INRA Prod. Anim., 14: 323-335.

Chillard,Y., Ferlay, A., Rouel, J. and Lambert, G. 2003. A review of nutritional and physiological factors affectng goat milk lipid synthesis and lipolysis. J. Dairy Sci., 86: 1751-1770.

Chilliard, Y., Rouel, J. and Leroux, C. 2006. Goat's alpha-s1 casein genotype influences its milk fatty acid composition and delta-9 desaturation melhorar os aspectos qualitativos do leite de cabra, agregando assim, maior valor funcional a este alimento, sem comprometer demasiadamente a sua produção.

ratios. Anim. Feed Sci. Tech., 131: 474-487.

Cook, M.C., Miller, C.C., Park, Y. and Pariza, M.W. 1993. Immune modulation by altered nutrient metabolism: Nutritional control of immuneinduced growt depression. Poultry Sci., 72: 1301-1305.

Eifert, E.C., Santos, P.P., Leite, L.C., Lanna, D.P.D. e Bomfim, M.A.D. 2006. Efeito de doses de óleo de mamona sobre a digestibilidade in vitro do capim elefante. Em: Reunião Anual da Sociedade Brasileira de Zootecnia, v. 43. Sociedade Brasileira de Zootecnia. João Pessoa.

Feng, S., Lock, A.L. and Garnsworthy, P.C. 2004 Technical note: a rapid lipid separation method for determining fatty acid composition in milk. J. Dairy Sci., 87: 3785-3788.

Hartman, L. and Lago, R.C.A. 1986. Rapid preparation of fatty acids methyl esters. Lab. Pratice, 22: 475-476.

Koning, F.L.H.A. e Schaafsma, G. 1997. A composição do leite de cabra. Uma pesquisa literária. TNO-Relatório, v. 97. 350. pp. 1-38.

Maia, F.J., Branco, A.F., Mouro, G.F., Coneglian, S.M., Santos, G.T., Minella, T.F. e Guimarães, K.C. 2006. Inclusão de fontes de óleo na dieta de cabras em lactação: produção, composição e perfil dos ácidos graxos do leite. Rev. Bras. Zootecn., 35: 1504-1513.

Mendes, R.S., Nóbrega, G.H., Silva, A.M.A., Azevedo, S.A., Silva, G.L.S., Mangueira, M.F.M. e Oliveira, M.D. 2007. Avaliação do consumo e da produção de leite de cabras suplementadas com diferentes fontes de lipídeos. Em: Anais do III Simpósio Internacional sobre Caprinos e Ovinos de Corte. João Pessoa. Paraíba.

Mesquita, I.V.U., Costa, R.G., Queiroga, R.C.R.E.e Medeiros, A.N. 2004. E feito da dieta na composição química e características sensoriais do leite de cabras. Em: Revista do Instituto de Laticínios Cândido Tostes. Juiz de Fora. 59. n. 337.

Nicolosi, R.J., Courtemanche, K.V., Laitinen, L., Scimeca, J.A. and Huth, P.J. 1993. Effect of 


\section{SANTOS ETAL.}

fedding diets enriched in conjugated linoleic acid on lipoproteins and aortic atherogenesis in hamster. Circulation, 88: 451-457.

Nudda, A., Battacone, G. and Bencini, R. 2002.

Nutrition and milk quality. In: Pulina, G. (Ed.).

Dairy sheep feeding and nutrition. Avenue Media. Bologna. pp. 197-228.

NRC. 1989. Nutrient requirements of dairy cattle, $6^{a}$ ed. National Academic Press. Washington D.C. 158 pp.

Parodi, P.W. 2003. Anti-cancer agents in milkfat. Aust. J. Dairy Technol., 58: 114-118.
Queiroga, R.C.R.E. e Costa, R.G. 2003. Qualidade nutricional e sensorial do leite caprino e seus derivados. Anais do $2^{\circ}$ SINCORTE. João Pessoa. pp. 313-328.

SAEG. 2007. Sistema para análises estatísticas e genéticas. Versão 9.1. Fundação Arthur Bernardes. Universidade Federal de ViçosaUFV. Viçosa.

Silva, M.M.C. 2005. Suplementação de lipídeos em dietas de cabras leiteiras. Tese de doutorado. Universidade Federal de Viçosa-UFV. Viçosa. 108 pp.

Archivos de zootecnia vol. 60, núm. 229, p. 122. 